\title{
Prospective Randomised Study To Compare Inj Dexmedetomidine And Inj Clonidine As Adjuvant To Bupivacaine Used For Ultrasound Guided Subclavian Perivascular And Axillary Block In Upper Limb Surgeries
}

\author{
Shashikant Shinde ${ }^{1}$, Deepa Kane ${ }^{2}$, Sunil Patil ${ }^{3}$ \\ ${ }^{I}$ Associate Professor, Department of Anaesthesiology, Critical Care \& Pain, Seth G S Medical College \& KEM \\ Hospital, Mumbai, India \\ .$^{2}$ Professor, Department of Anaesthesiology, Critical Care \& Pain, Seth G S Medical College \& KEM Hospital, \\ Mumbai, India. \\ ${ }^{3}$ Student, Department of Anaesthesiology, Critical Care \& Pain, Seth G S Medical College \& KEM Hospital, \\ Mumbai, India.
}

\begin{abstract}
:
Background: Ultrasound continues to grow in popularity as a method of nerve localization and it has the advantage of allowing real time visualization of the plexus, pleura and vessels along with the needle and local anaesthetic spread. ${ }^{[4]}$ So this study intends to compare efficacy and safety of Inj.clonidine and Inj.Dexmedetomidine as adjuvant to local anaesthetic for USG guided subclavian perivascular and axillary block in upper limb surgeries.

Materials and Methods: We conducted this study as a prospective randomized study. A total of 70 adult patients were randomly selected who fulfilled the inclusion criteria. They were divided into groups and study was conducted.

Results: In this study, we measured the results of each drug by its action on onset and peak of sensory and motor blockade and duration of blockade.

Conclusion: From our study we conclude that both Clonidine and Dexmeditomidine with local anaesthetics promote satisfactory anaesthesia for upper limb surgeries. Onset and duration sensory blockade of clonidine group is faster and duration of sensory blockade is more than dexmeditomidine group as adjuvant to local anaesthetics in USG guided subclavian pervascular block plus axillary block.
\end{abstract}

Keywords: lignocaine, bupivacaine, clonidine, dexmeditomidine, usg guided blocks.

\section{Introduction}

Brachial plexus blocks provide a useful alternative to general anaesthesia for upper limb surgeries. They achieve near ideal operating conditions by producing complete muscular relaxation and maintaining stable intra-operative hemodynamic conditions. The sympathetic block which they produce reduces postoperative pain, vasospasm and edema. Peripheral nerve blocks are gaining widespread popularity for perioperative pain management because of their specific advantages over general anaesthesia and central neuraxial anaesthesia. Pain relief with PNB avoids side effects such as somnolence, nausea and vomiting, hemodynamic instability and voiding difficulty inherent to general and central neuraxial anaesthesia. Patients who undergo surgery under PNB can bypass phase I recovery room and frequently be discharged expeditiously following ambulatory surgery.Patients with unstable cardiovascular disease can undergo surgery under PNB without significant hemodynamic changes. Patients who have abnormalities in haemostasis or infection which contraindicate use of central neuraxial block can be candidates for surgery under PNB.A substantial savings in operating room turnover time can occur if PNB is done outside the operating room. Patients with a PNB can frequently position themselves. When used as part of a combined general regional technique, PNB facilitates lighter planes of anaesthesia, avoiding the use of opioids and allowing a quick emergence

and recovery. Compared with general anaesthesia, peripheral nerve block improves early outcome after upper limb surgeries. ${ }^{[1]}$ There has always been search for adjuvants to the regional nerve block with drugs that prolong the duration of analgesia with lesser adverse effects.Alpha2 adrenergic receptor agonists have been the focus of interest for their sedative, analgesic, perioperative, sympatholytic and cardiovascular stabilizing effects with reduced anaesthetic requirements. ${ }^{[2]}$ Dexmedetomidine, a potent alpha 2 adrenoceptar agonist , is approximately eight times more selective towards the alpha 2 adrenoceptar than clonidine. ${ }^{[3]}$ The current study was designed to test the hypothesis that Dexmedetomidine when added as an adjuvant to local anaesthetic in subclavian perivascular and axillary block enhanced duration of sensory and motor block, duration of analgesia, quality of block as compared to clonidine. The regional nerve block of the upper limb is a useful technique. 
Regional nerve block of the brachial plexus provides ideal operating conditions for the surgeon because it provides complete relaxation of the muscles of the upper extremity thus simplifying closed reduction of fractures and dislocations or the approximation of severed tendons, sympathetic block of the blood vessels which lessens post-operative vasospasm pain and oedema. Ultrasound continues to grow in popularity as a method of nerve localization and it has the advantage of allowing real time visualization of the plexus, pleura and vessels along with the needle and local anaesthetic spread. ${ }^{[4]}$ So this study intends to compare efficacy and safety of Inj.clonidine and Inj.Dexmedetomidine as adjuvant to local anaesthetic for USG guided subclavian perivascular and axillary block in upper limb surgeries.

\section{Aims and Objectives}

To compare Dexmedetomidine vs clonidine as adjuvant to local anaesthetic for subclavian perivascular and axillary block in upper limb surgeries in terms of following parameters:

1. Onset of sensory blockade.

2. Onset of motor blockade.

3. Duration of sensory blockade.

4. Duration of motor blockade.

5. Quality of analgesia of these two drugs in postoperative period.

And to study side-effects if any of these two drugs.

\section{Material and methods}

STUDY AREA - Tertiary teaching institute

STUDY DURATION - 1 year

STUDY DESIGN - Prospective randomized study

SAMPLE SIZE

As per Swami etal standard deviation in onset of sensory block will be 1.21 in clonidine group and standard deviation in dexmeditomidine group will be 1.28 mean difference in onset of sensory block between two group will be $0.82 \mathrm{~min}$. Alpha error will be $5 \%$ and power of study will be $80 \%$.

So that total patient per group will be 35 per group.This is a prospective randomised study of 70 cases, after obtaining approval from ethics committee of Seth GSMC and KEM hospital and informed consent from patients who fulfil the inclusion criteria, cases will be divided randomly into two groups as-

GROUP A: will receive Inj. bupivacaine $(0.5 \%) 15 \mathrm{cc}$ and injection adrenalized lignocaine $15 \mathrm{cc}$,Injection Clonidine $(1 \mathrm{mic} / \mathrm{kg})$.

GROUP B: will receive Injection bupivacaine $(0.5 \%) 15 \mathrm{cc}$ and injection adrenalized lignocaine $15 \mathrm{cc}$ and inj. Ilection Dexmedetomidine $(0.5 \mathrm{mic} / \mathrm{kg})$.

\section{INCLUSION CRITERIA:}

1. Patients undergoing upper limb surgeries including midshaft humerus and below midshaft humerus

2. ASA grade 1 and 2 .

3. Age between 18 to $60 \mathrm{yrs}$.

4. Weight 50 to $70 \mathrm{~kg}$

\section{EXCLUSION CRITERIA:}

1. .Patients own refusal for participation.

2. ASA grade 3 and 4.

3. Age $<18 \mathrm{yrs}$ and $>60 \mathrm{yrs}$.

4. Co-existing severe cardiovascular, respiratory or neurological disorders.

5. Known history of coagulation disorders.

6. Inflammatory skin lesions at the site of giving block.

7. Pre-existing neuropathies.

8. Allergy to local anaesthetics.

9. .Pregnant mothers and lactating mothers.

10. Weight less than $50 \mathrm{~kg}$

\section{METHOD:}

A written consent will be obtained from all the patients included in this study just before the surgery and patients will be randomly assigned to receive $30 \mathrm{ml}$ of these two different solutions. Group 1 will receive Inj. bupivacaine (0.5\%) $15 \mathrm{ml}$ and Inj. Adrenalized Lignocaine (2\%) $15 \mathrm{ml}$ and inj clonidine $1 \mathrm{mic} / \mathrm{kg}$ and Group 2 will receive Inj.bupivacaine $(0.5 \%) 15 \mathrm{ml}$ and Inj. Adrenalized lignocaine( $2 \%$ ) 15ml.and inj Dexmedetomidine $0.5 \mathrm{mic} / \mathrm{kg}$ 
Patients will be taken up for surgery after adequate starvation of $6 \mathrm{hrs}$.

All patients will be brought to the pre-operative holding area and will be monitored using standard ASA monitors. Patients will be sedated with i.v. midazolam $(0.03 \mathrm{mg} / \mathrm{kg})$ and i.v. fentanyl $(1 \mathrm{mcg} / \mathrm{kg})$ titrated to Ramsay sedation scale. The patient will be taken into the operation theatre and i.v.access will be taken, noninvasive monitoring will be applied using ECG, pulse oximetry and NIBP. Oxygen at $5 \mathrm{lt} /$ minute with Hudson's mask will be supplemented.

\section{Positioning}

In the supine position with arm place by the side head turned to opposite side for subclavian perivascular block. For axillary block in supine position arm will be abducted and elbow flexed at 90 degree and externally rotated. The skin will be cleaned with an appropriate solution such as $2 \%$ chlorhexidine in 70\%isopropyl alcohol solution.

\section{Equipment}

A High frequency $(10-15 \mathrm{Mhz})$ linear probe and a $22 \mathrm{~g} 5 \mathrm{~cm}$ stimulpex needle will be choosen. Our preferred local anaesthetic will be 50:50 $2 \%$ adrenalized lignocaine and $0.5 \%$ bupivacaine, inj clonidine inj Dexmedetomidine

\section{Drugs for study}

Bupivacaine, Adrenalized Lignocaine, clonidine and Dexmetedomidine are available on $\underline{\text { Schedule }}$

\section{Sample for Study}

Patients for sample of study are all recruited from orthopaedic department which include fracture midshaft and below midshaft of humerus.

\section{Scanning Technique, nerve localization and needle placement}

The probe will be placed in supraclavicular fossa in coronal oblique plane. The pulsating hypoechoic subclavian artery will be identified. While maintaining the view of the artery the probe will be then angled until both the first rib and the pleura are also seen simultaneously .Rib generates a bony shadow whilst the lung will be specular reflector and therefore grainy image will be seen below hyperechoic pleura. The hypoechoic nerve structures (trunks or divisions) will be visualised .

Needle will be inserted in lateral to medial direction in the long axis of transducer .Local anaesthetic spread will be observed during injection and needle repositioned to ensure distribution around all the nerve trunks within plexus sheath. $18 \mathrm{ml}$ of local anaesthetic drug will be injected in subclavian perivascular block only after negative aspiration for blood.

Axillary block will be performed in the proximal axilla. The ideal location for local anaesthetic injection will be between nerve and artery so that separation between two structure occur. The musculocutaneous nerve is usually blocked within coracobrachialis where its flat shape gives large amount of surface area for rapid block of both sensory and motor fibres. $12 \mathrm{ml}$ of drug will be injected in axillary block (3cc for ulnar nerve, $3 \mathrm{cc}$ for median nerve, $3 \mathrm{cc}$ for radial nerve, $3 \mathrm{cc}$ for musculocutaneous nerve)

Thus, the total volume of the study drug used will be $30 \mathrm{ml}$.

The sensory block (analgesia-loss of the sharp sensation of pin-prick, anaesthesia-loss of the sensation of touch) will be determined with a short- beveled 27 gauge needle. The innervation areas of the ulnar, median, radial, musculocutaneous will be tested. Sensory block will be assessed by the pin prick method. Assessment of sensory block will be done at each minute after completion of drug injection in the dermatomal areas corresponding to median nerve, radial nerve, ulnar nerve and musculocutaneous nerve till complete sensory blockade. Sensory onset will be considered when there will be a dull sensation to pin prick along the distribution of any of the above-mentioned nerves. Complete sensory block was considered when there was complete loss of sensation to pin prick

Sensory block graded as

Grade 0: Sharp pin felt

Grade 1: Analgesia, dull sensation felt

Grade 2: Anaesthesia, no sensation felt.

Assessment of motor block will be carried out by the same observer at each minute till complete motor blockade after drug injection. Onset of motor blockade will be considered when there will be Grade 1 motor blockade. Peak motor block will be considered when Grade 2 motor blockade. Motor block will be determined according to a modified Bromage scale for upper extremities on a 3-point scale.

Grade 0: Normal motor function with full flexion and extension of elbow, wrist and fingers 
Grade 1: Decreased motor strength with ability to move the fingers only

Grade 2: Complete motor block with inability to move the fingers

The block will be considered incomplete when any of the segments supplied by median, radial, ulnar and musculocutaneous nerve not have analgesia even after $30 \mathrm{~min}$ of drug injection. These patients will be supplemented with intravenous fentanyl $(1 \mu \mathrm{g} / \mathrm{kg})$ and midazolam $(0.03 \mathrm{mg} / \mathrm{kg})$. When more than one nerve remained unaffected, it was considered a failed block. In this case, general anaesthesia will be given intraoperatively. Patients were monitored for haemodynamic variables such as heart rate, blood pressure and oxygen saturation every $30 \mathrm{~min}$ after the block intraoperatively and every $60 \mathrm{~min}$ post-operatively. Sedation of patient was assessed by the Ramsay Sedation Score. At the end of the procedure, quality of operative conditions were assessed according to the following numeric scale :

Grade 4: (Excellent) No complaint from patient

Grade 3: (Good) Minor complaint with no need for the supplemental analgesics

Grade 2: (Moderate) Complaint that required supplemental analgesia

Grade 1: (Unsuccessful) Patient given general anaesthesia

Assessment of blood loss will be done and fluid will be administered as per the loss. Duration of surgery noted. The intra- and post-operative assessment will be done by an anaesthesiologist who will be unaware of the drug used. Patients will be assessed for duration of analgesia as per a numeric rating scale of 0 to 10 . The numeric rating scale was recorded post-operatively every 60 min till the score of 5.

At the conclusion of the surgery, all patients will be transferred to the recovery room and reassessed to confirm sensory and motor blockade. In order to evaluate sensation, patients will be asked to document the time of first oral narcotic, the time when incisional discomfort began and the time when full sensation returned to the forearm and hand. Other parameters which would be assesed will be PR, BP, RR, SpO2 and any complications of subclavian perivascular and axillary block.

DEMOGRAPHICAL DATA

IV. Observation and results

Sex distribution

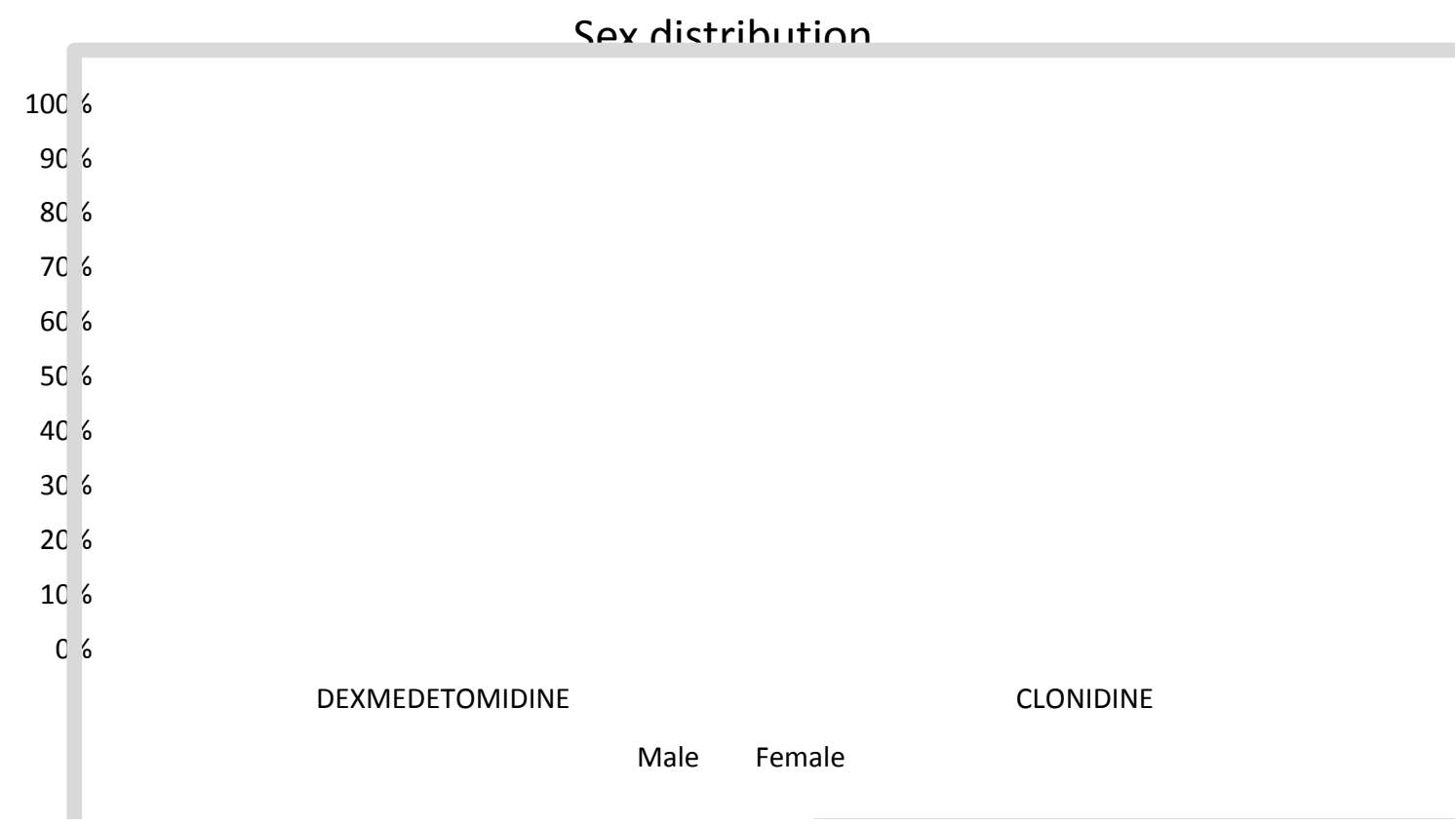

\section{Chi square test}

The proportion of males in the Dexmedetomidine group was $65.71 \%$ and clonidine group was $62.86 \%$, while that of females was $34.29 \%$ and $37.4 \%$ respectively. On comparing the two groups it was observed that the sex distribution in the two groups was comparable. 
AGE

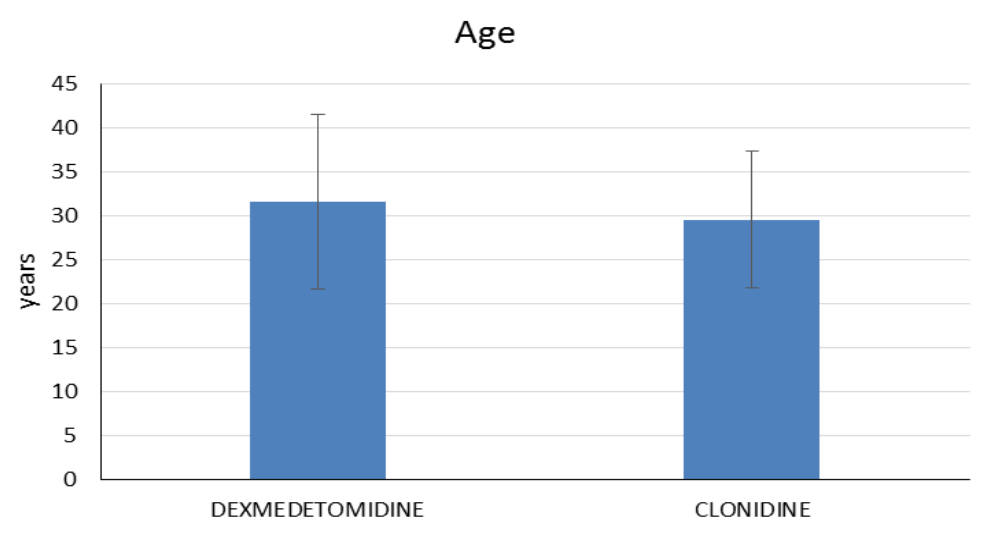

\section{Mann Whitney test}

The mean age of patients in the dexmedetomidine group was $31.62 \pm 9.92$ years and in clonidine group was $29.57 \pm 7.808$ years. On comparing the two groups, it was found that the age distribution of the two groups is comparable.

\section{Weight}

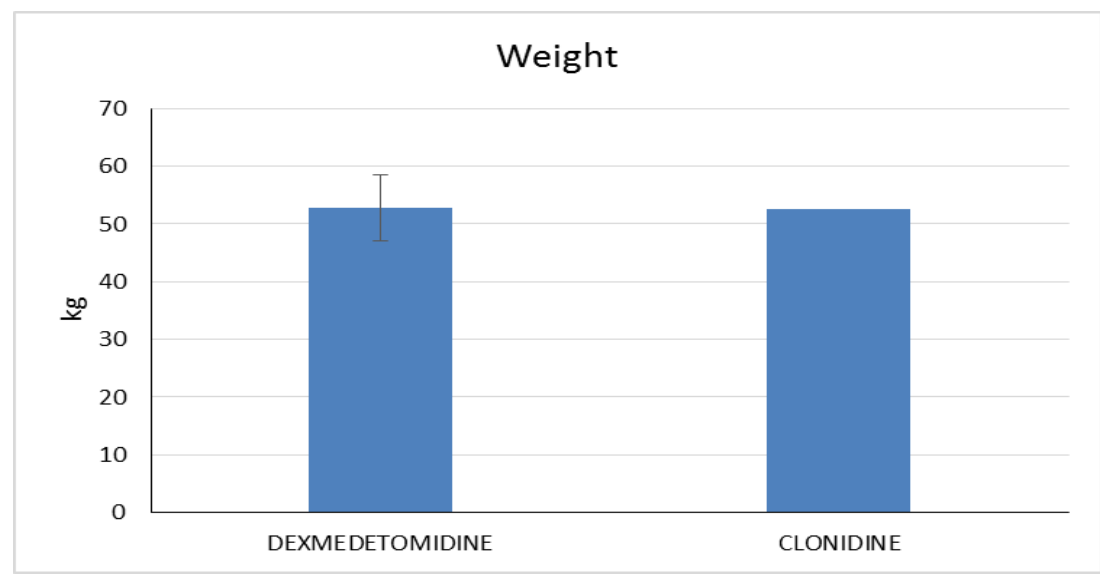

Mann Whitney test

The mean weight of the patients in the dexmedetomidine group was $52.77 \pm 5.78 \mathrm{~kg}$ and in clonidine group was $52.68 \pm 6.65 \mathrm{~kg}$. On comparing the two groups for weight it was noted that the weight distribution of the two groups is comparable.

\section{Onset of sensory blockade}

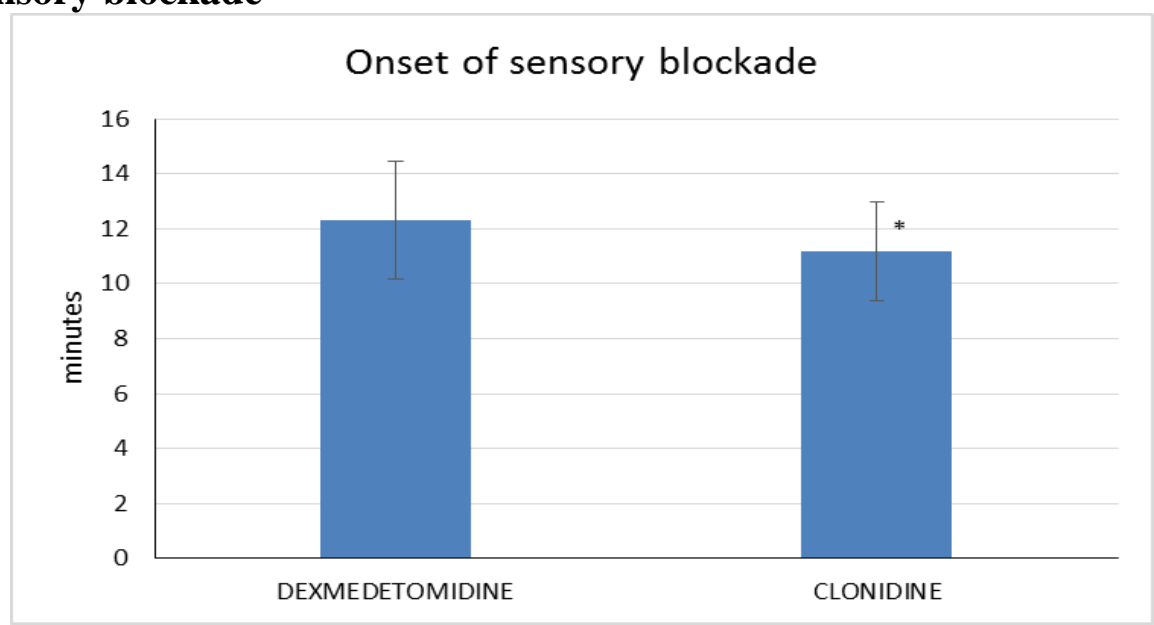




\section{Mann Whitney test}

In the Dexmedetomidine group the mean onset of sensory blockade was after $12.31 \pm 2.13$ minutes while that in the clonidine group was after $11.17 \pm 1.79$ minutes. On comparing the onset of sensory blockade in the two groups it was found that the sensory blockade occurs significantly faster in the clonidine group than the dexmedetomidine group.

\section{Duration of sensory blockade}

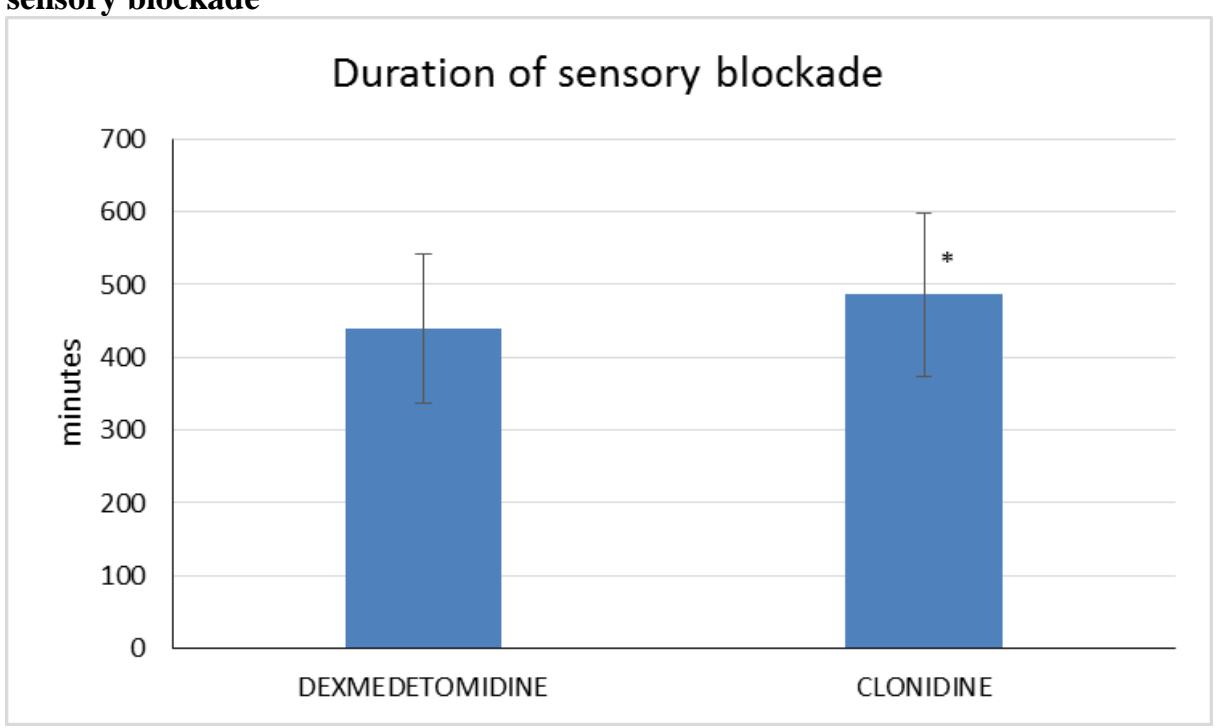

\section{Mann Whitney test}

The mean duration of sensory blockade in the Dexmedetomidine group was $439.43 \pm 103.30$ minutes and that in the clonidine group was $486.57 \pm 111.91$ minutes. On comparing the duration of sensory blockade in the 2 groups it was observed that the duration of sensory blockade is significantly longer in the clonidine group than the dexmedetomidine group.

\section{Onset of motor blockade}

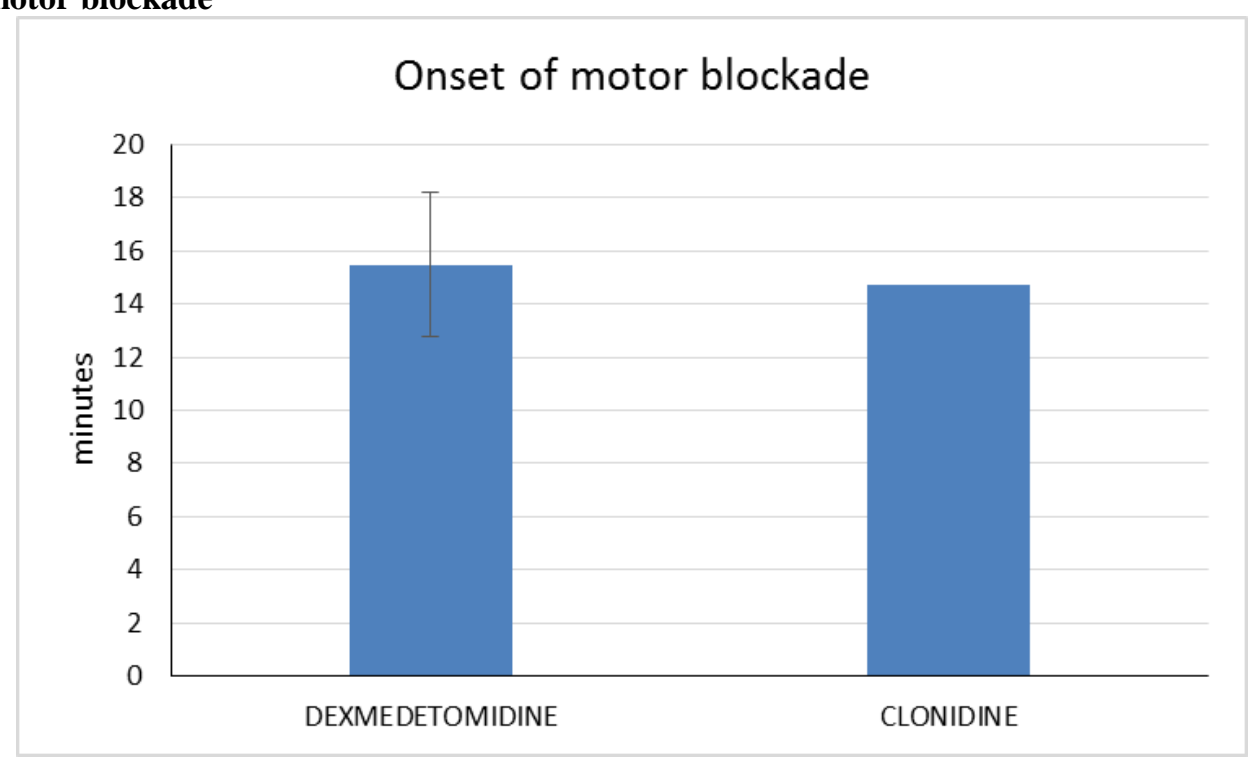

\section{Mann Whitney test}

In the Dexmedetomidine group the mean onset of motor blockade was after $15.48 \pm 2.69$ minutes while that in the clonidine group was $14.74 \pm 2.26$ minutes. On comparing the onset of motor blockade in the two groups it was observed that the time for onset of motor blockade is comparable between the two groups. 


\section{Duration of motor blockade}

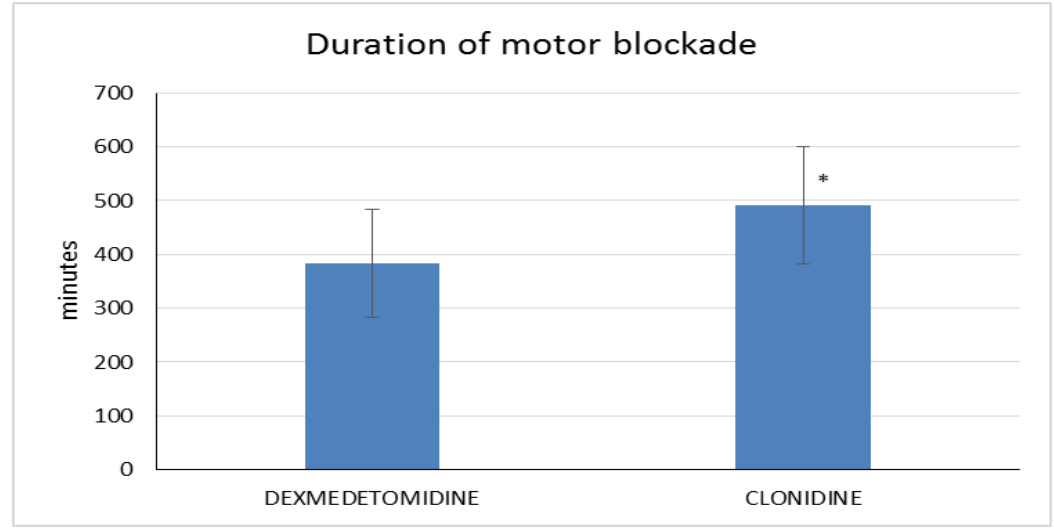

\section{Mann Whitney test}

The mean duration of the motor blockade in the Dexmedetomidine and the clonidine groups was $383.71 \pm 100.76$ and $490.83 \pm 108.54$ minutes, respectively. On comparing the duration of the motor blockade in the two groups it was observed that the duration of motor blockade is significantly longer in the clonidine group than the Dexmedetomidine group.

\section{Time for rescue analgesia}

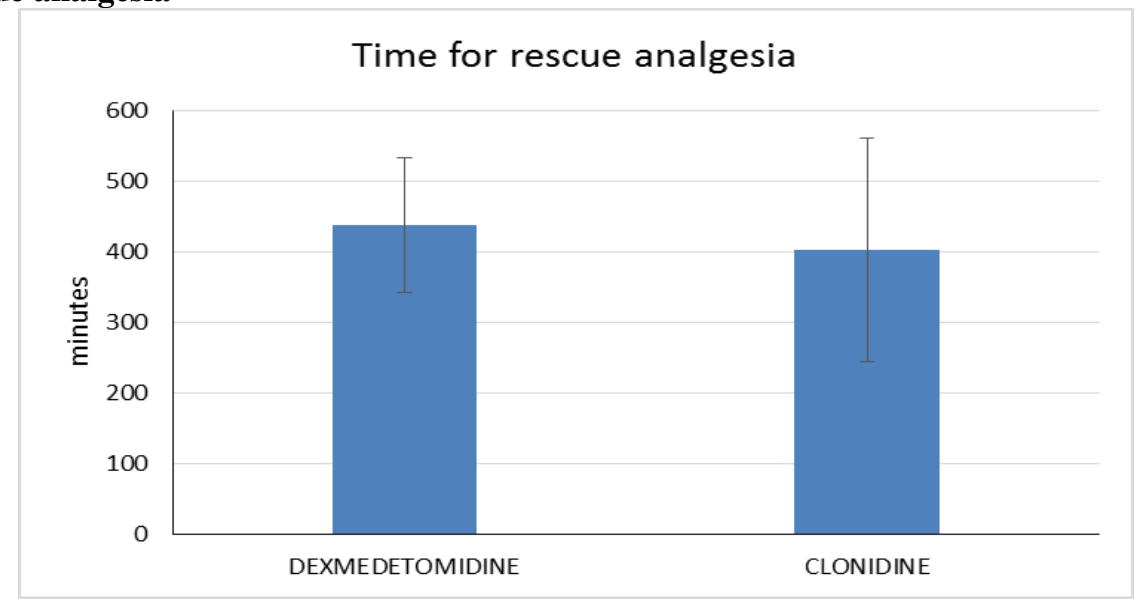

\section{Mann Whitney test}

The mean time for rescue analgesia in the Dexmedetomidine group was $437.14 \pm 94.94$ minutes and that in the clonidine group was $402.51 \pm 157.70$ minutes. On comparing the two groups, it was observed that the time for rescue analgesia is comparable between two groups.

\section{Quality of analgesia}

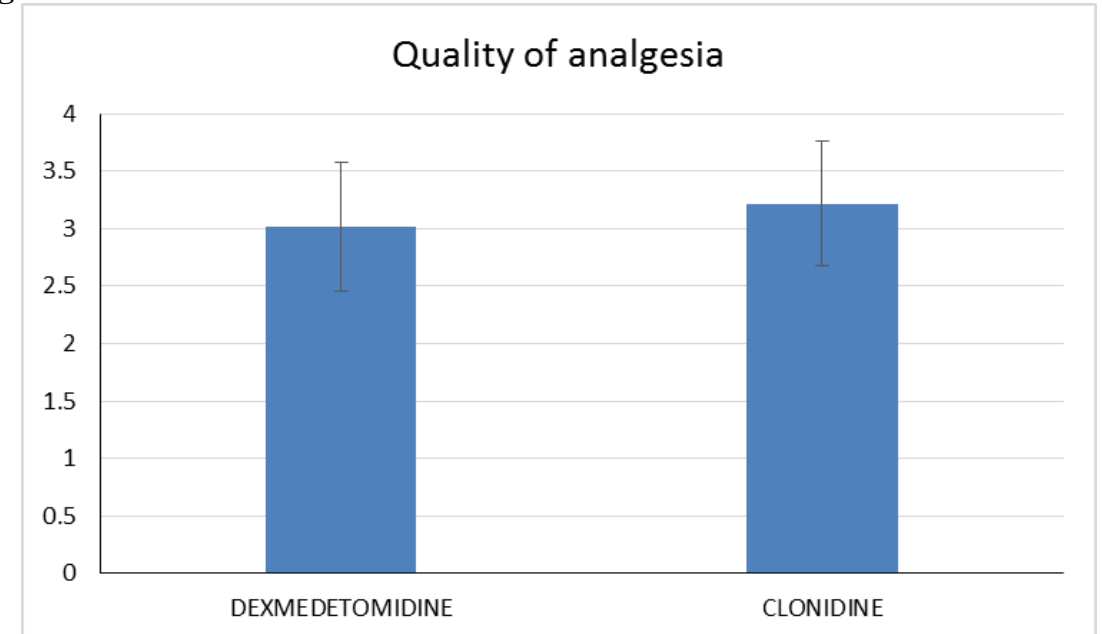




\section{Mann Whitney test}

The mean score of quality of analgesia in the Dexmedetomidine and the clonidine groups was $3.02 \pm$ 0.56 and $3.22 \pm 0.54$, respectively. On comparing the two groups it was found that the quality of analgesia is comparable between the two groups.

\section{Pulse rate}

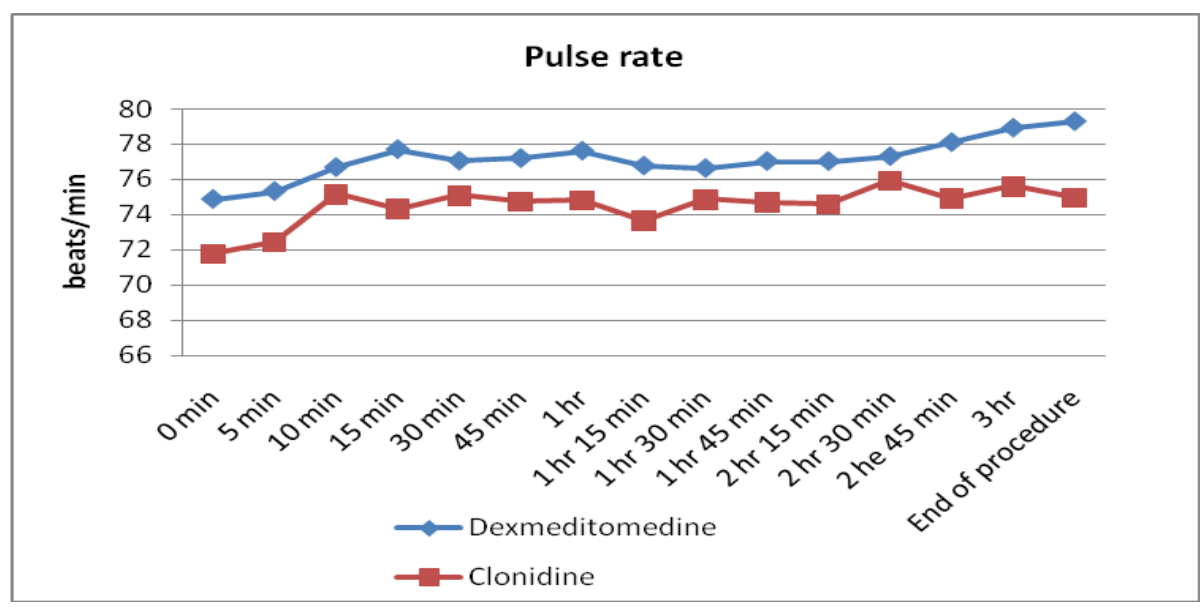

The variables at various times have been compared between the two groups by Mann Whitney Test. $\left({ }^{\#}\right.$ Unpaired t test) The pulse rate (beats/minute) at various intervals was measured in the Dexmedetomidine and clonidine groups and was compared. It was noted that the pulse rate in the Dexmedetomidine group was significantly higher than the clonidine group at 15 minutes $(77.71 \pm 7.46$ vs $74.31 \pm 6.62), 2 \mathrm{hr} 45$ minutes $(78.11 \pm 6.80$ vs $74.91 \pm 6.25), 3$ hours $(78.94 \pm 6.66$ vs $75.60 \pm 6.24)$ and at the end of procedure $(79.31 \pm$ 6.601 vs $74.97 \pm 6.16)$. The pulse rate was comparable in the Dexmedetomidine and clonidine groups at the remaining time intervals.

\section{Systolic blood pressure}

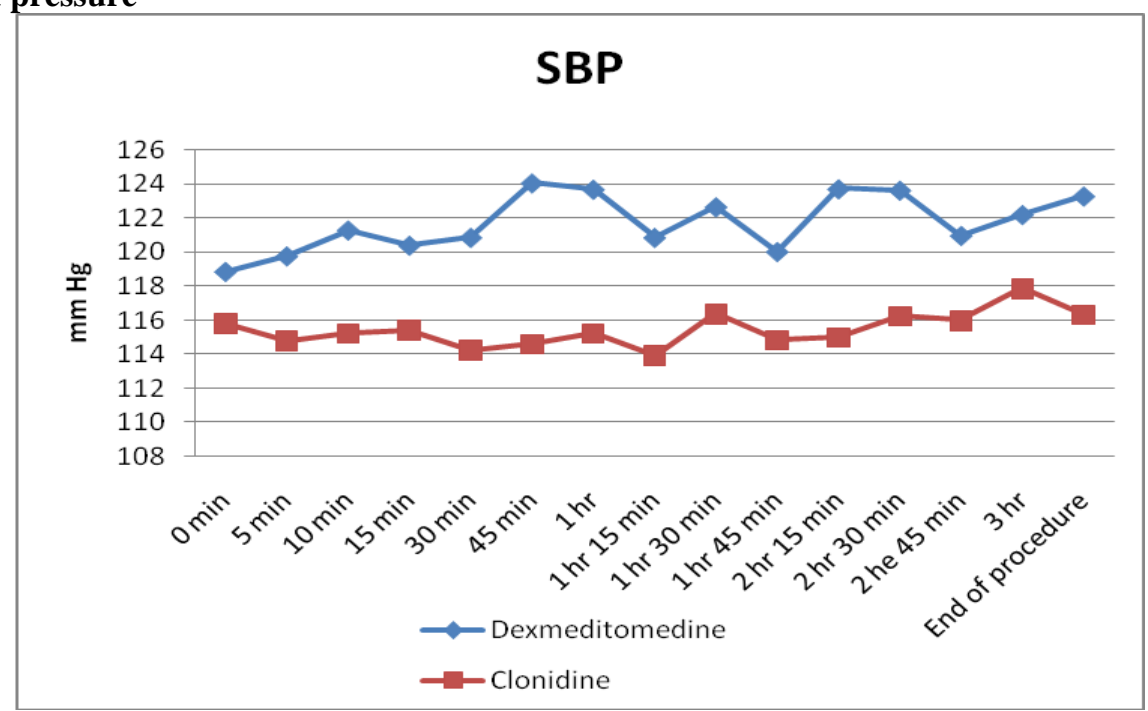

The variables at various times have been compared between the two groups by Mann Whitney Test.

The systolic blood pressure was measured in both groups and was compared at various time intervals. It was observed that the systolic blood pressure $(\mathrm{mmHg})$ in the Dexmedetomidine group was significantly higher than the clonidine group at 5 minutes $(119.77 \pm 9.11$ vs $114.80 \pm 6.25), 10$ minutes $(121.29 \pm 8.53$ vs $115.26 \pm 6.41), 15$ minutes $(120.4 \pm 8.96$ vs $115.43 \pm 5.81), 30$ minutes $(120.86 \pm 9.18$ vs $114.29 \pm 5.53), 45$ minutes $(124.06 \pm 9.26$ vs $114.63 \pm 6.208), 1$ hour $(123.69 \pm 9.66$ vs $115.26 \pm 5.88), 1$ hr 15 minutes $(120.34 \pm$ 8.92 vs $113.66 \pm 6.42)$, 1 hour 30 minutes $(122.66 \pm 9.48$ vs $116.40 \pm 7.54), 1 \mathrm{hr} 45$ minutes $(120.03 \pm 9.05$ vs $114.86 \pm 5.88), 2$ hours $15 \min (123.71 \pm 9.39$ vs $115.03 \pm 6.71), 2$ hours 30 minutes $(123.63 \pm 8.94$ vs 116.26 $\pm 6.67), 2 \mathrm{hr} 45$ minutes $(120.97 \pm 8.85 \mathrm{vs} 116 \pm 6.58)$, and at the end of the procedure $(123.29 \pm 1.68 \mathrm{vs}$ $116.34 \pm 6.79)$. 


\section{Diastolic blood pressure}

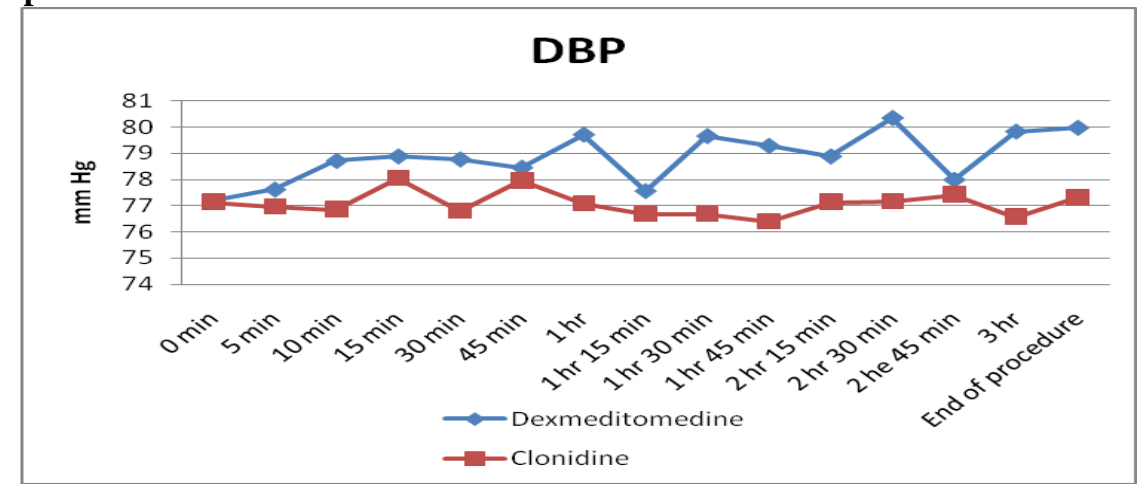

The variables at various times have been compared between the two groups by Mann Whitney Test.

The diastolic blood pressure was measures in the two groups and was compared. It was noted that the diastolic blood pressure $(\mathrm{mmHg})$ in the Dexmedetomidine group was significantly higher than the clonidine group at 10 minutes $(78.71 \pm 3.32$ vs $76.85 \pm 3.85), 30$ minutes $(78.77 \pm 4.09$ vs $76.80 \pm 3.4)$, 1 hour $(79.71 \pm 5.205$ vs $77.08 \pm 3.64)$, 1 hour 30 minutes $(79.65 \pm 4.07$ vs $76.68 \pm 3.104)$, 2 hour 30 minutes $(80.34 \pm 3.91$ vs $77.17 \pm$ $2.99), 3$ hours $(79.82 \pm 4.63$ vs $76.57 \pm 4.18)$ and at the end of the procedure $(79.97 \pm 4.66$ vs $77.31 \pm 3.59)$.

\section{SPO2}

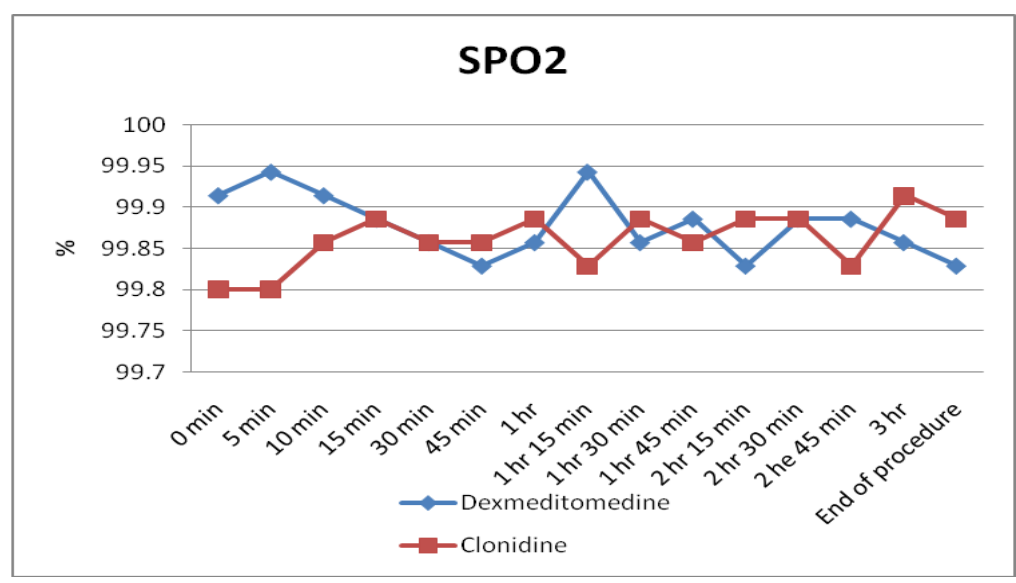

The variables at various times have been compared between the two groups by Mann Whitney Test.

The SpO2 was noted at regular time intervals in the Dexmedetomidine and clonidine groups and when compared, was found to comparable in both groups at all the time intervals.

\section{Respiratory rate}

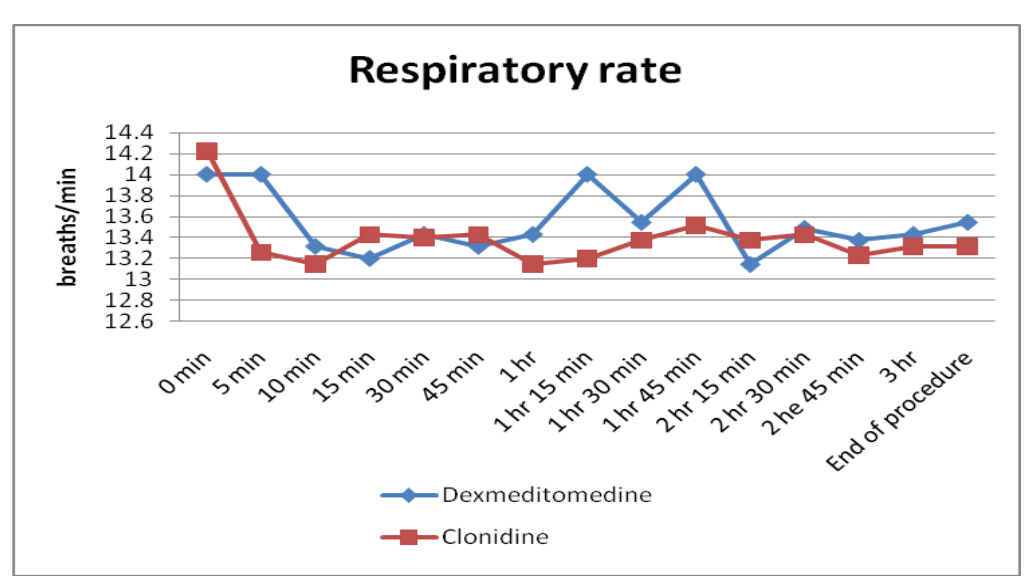

The variables at various times have been compared between the two groups by Mann Whitney Test.

The respiratory rate (per minute) was notes at various time intervals in the Dexmedetomidine and clonidine groups and was compared. It was found that the respiratory rate in the Dexmedetomidine group was 
significantly higher than the clonidine group at 0 minutes $(14 \pm 0.48$ vs $13.22 \pm 1.19), 5$ minutes $(14 \pm 0.48$ vs $13.20 \pm 1.106)$ and $1 \mathrm{hr} 15$ minutes $(14 \pm 0.48 \mathrm{vs} 13.25 \pm 1.09)$. At later intervals the respiratory rate was comparable between the two group.

\section{Discussion}

In study by Bajwa SJS et al, the mean age of the patients in the Dexemedetomidine group was 50.38 years and in clonidine group was 52.06 years ${ }^{[26]}$ Dexmedetomidine and clonidine groups in the Swami SS et al study had comparable mean ages of 33.83 and 33.73 years, respectively ${ }^{[27]}$ The mean age of patients in the Dexmedetomidine and clonidine groups in the study by Babu MSS et al, was 47.86 and 48.9 years, respectively ${ }^{[28]}$ In a study by Mahendru V et al, the mean age of the patients in the Dexmedetomidine was 37.8 years and clonidine group was 37 years ${ }^{[29}$ In a study by Raval et al, the mean age of the patients in the Dexmedetomidine and clonidine groups was 36.8 and 32.75 years respectively. ${ }^{30]}$ The mean age of patients in the Dexmedetomidine (31.62 years) and clonidine (29.57 years) in the current study was lower compared to the other studies. Thus, many studies of comparing Dexmedetomidine with clonidine have been carried out in adults but studies in the age group below 20 years are lacking.

The proportion of males in the Dexmedetomidine and clonidine groups in the Swami SS et al study was $63.33 \%$ and $73.33 \%$ respectively while the proportion of the females was $36.67 \%$ and $26.67 \%$ respectively. The sex distribution in the Swami SS et al study was comparable. ${ }^{[27]}$ The sex distribution findings in our study were similar to those in the Swami SS et al study. The proportion of males and females in the current study was $65.71 \%$ and $34.29 \%$ in Dexmedetomidine group and $62.86 \%$ and $37.4 \%$, respectively in clonidine group and there was no difference in the sex distribution between the two groups.

In the study Bajwa SJS et al, the mean weight of the patients in the Dexmedetomidine group was 56.94 $\mathrm{kg}$ and in clonidine group was $58.26 \mathrm{~kg} .{ }^{[26]}$ Dexmedetomidine and clonidine groups in the Swami SS et al study had comparable weights of 54.3 and $58.4 \mathrm{~kg}$, respectively. ${ }^{[33]}$ The mean weight of patients in the Dexmedetomidine and clonidine groups in the study by Babu MSS et al, was 60.26 and $59.1 \mathrm{~kg}$, respectively. [28]In a study by Mahendru V et al, the mean weight of the patients was $66.6 \mathrm{k}$ in Dexmedetomidine group and $69.3 \mathrm{~kg}$ in clonidine group. ${ }^{[29]}$ In a study by Raval et al, the mean weight of the patients in the Dexmedetomidine and clonidine groups was 59.4 and $57.24 \mathrm{~kg}$ respectively. ${ }^{\left[{ }^{30]}\right.}$ The weight in our study in the Dexmedetomidine group was $52.77 \mathrm{~kg}$ and in clonidine group was $52.68 \mathrm{~kg}$. Thus, the weight of the patients in the two groups was similar in the other studies and the finding of indifferent weights in the two groups was similar to that in the other studies.

In the study by Bajwa SJS, the onset of sensory blockade in the Dexemdetomidine group was 8.52 minutes and in the clonidine group was 9.72 minutes signifying earlier onset in the Dexmedetomidine group ${ }^{[26]}$ The Swami SS et al study showed that the onset of sensory blockade in the Dexmedetomidine group $(1.77 \mathrm{~min})$ was faster than the clonidine group $(2.33 \mathrm{~min}) .{ }^{[27]}$ No difference was noted in the onset of sensory blockade in the two groups in the Solanki SL et al study. ${ }^{[31]}$ The time of onset of sensory blockade in the Mahendru V et al study was not different in the Dexmedetomidine $(8.3 \mathrm{~min})$ and clonidine $(8.3 \mathrm{~min})$ groups. ${ }^{\text {[29] }}$ In a study by Raval et al, the onset of sensory block was 51 seconds in Dexmedetomidine and 58 seconds in clonidine group and were statistically insignificant. ${ }^{[30]}$ In study by Rao LN, onset of sensory blockade was faster in the Dexmedetomidine group compared to the clonidine group.) In our study, the onset of sensory block in the clonidine group was $11.17 \mathrm{~min}$ and in the Dexmedetomidine group was $12.31 \mathrm{~min} .{ }^{[32]}$ This finding is in contrast to the findings regarding onset of sensory blockade in all the studies comparing Dexmedetomidine with clonidine. Our study has shown for the first time that the onset of sensory block by clonidine is faster than Dexmedetomidine.

In the Swami SS et al study, the duration of sensory block in the Dexemedetomidine group (413.97 $\min$ ) was higher than the clonidine group $(227 \mathrm{~min}) .{ }^{[27]}$ The duration of the sensory blockade was longer in the Dexmedetomidine group (146.7 $\mathrm{min}$ ) compared to the clonidine group (117 min) in study by Mahendru V et al. ${ }^{[29]}$ In a study by Raval et al, the total duration of sensory blockade was 296 minutes in Dexmedetomidine and 306 minutes in clonidine group and comparable in both groups. ${ }^{[30]}$ The duration of sensory block in our study was 439 minutes in the Dexmedetomidine group and 486 minutes in clonidine group. This finding was in contrast to the studies in the Swami SS et al, Mahendru V et al and Raval et al studies. Current study showed for the first time that the duration of the sensory blockade was longer in the clonidine group than the Dexmedetomidine group.

In the study by Bajwa SJS, the onset of motor blockade in the Dexemdetomidine group was 17.24 minutes and in the clonidine group was 19.52 minutes signifying earlier onset in the Dexmedetomidine group. ${ }^{[26]}$ The Swami SS et al study showed that the onset of motor blockade in the Dexmedetomidine group (4.65 min) was insignificantly longer than the clonidine group $(3.87 \mathrm{~min}) .{ }^{[27]}$ No difference was noted in the onset of motor blockade in the two groups in the Solanki SL et al study. ${ }^{[31]}$ The time of onset of motor blockade in the Mahendru V et al study was not different in the Dexmedetomidine $(9.7 \mathrm{~min})$ and clonidine $(9.8 \mathrm{~min})$ groups. ${ }^{[29]}$ 
In a study by Raval DL et al, the onset of motor block was 72 seconds in Dexmedetomidine and 79 seconds in clonidine group and were statistically insignificant. ${ }^{[30]}$ In study by Rao LN, onset of motor blockade was faster in the Dexmedetomidine group compared to the clonidine group. ${ }^{[32]}$ The time for onset of motor blockade was comparable in the Dexmedetomidine (15.48 min) and clonidine (14.74 min) in our study. This finding was similar to the studies by Swami SS et al, Solanki SL et al, Mahendru V et al and Raval DL et al. Findings of earlier onset of motor blockade in the Bajwa SJS et al and Rao LN studies was in contrast to the findings in our study.

The Swami SS et al study showed that the duration of the motor blockade in the Dexemdetomidine group (472.24 $\mathrm{min})$ was higher than the clonidine group $(292.67 \mathrm{~min}) .{ }^{[27]}$ The duration of the motor blockade was longer in the Dexmedetomidine group (273.3 min) compared to the clonidine group (198.7 min) in study by Mahendru V et al.[29] In a study by Raval et al, the total duration of motor blockade was 254 minutes in Dexmedetomidine and 262 minutes in clonidine group and comparable in both groups. [30]The current study demonstrated for the first time that the duration of the motor blockade was longer in the clonidine group (490 min) than the Dexmedetomidine group (383.71 min).

The mean time for rescue analgesia in the Bajwa SJS et al study in the Dexemdetomidine group was 342.88 minutes and was significantly more than that in the clonidine group (310.76 minutes). ${ }^{[26]}$ The need for rescue analgesia in both groups was nil in the study by Babu MSS et al. ${ }^{[28]}$ The findings of the Bajwa SJS study contradict the findings of our study wherein the time for rescue analgesia in the Dexmedetomidine group (437 min) was comparable to the clonidine group (402 min).

The side effects in the Bajwa SJS et al study in both groups were nausea, vomiting, shivering, headache, dizziness and dry mouth. ${ }^{[26]}$ Both groups in the Swami SS et al study had no side effects ${ }^{[27]}$ In the study by Mahendru V et al bradycardia was observed in one patient in Dexmedetomidine group and in two patients in the clonidine group. ${ }^{[29}$ In a study by Raval DL et al, there were no side effects in both groups. ${ }^{[30]}$ Our study had no occurrence of side effects in concordance with the studies by Swami SS et al and Raval DL et al. Our study validates the safety use of the two drugs for use in clinical practice. The high incidence of the side effects in the Bajwa SJS et al study may be due to concomitant drugs given.

The pulse rate in the Swami SS et al study was significantly lower in the Dexmedetomidine group than the clonidine group at 1 hour, 1 hour 30 minutes and 2 hours. ${ }^{[27]}$ The heart rate in study by Babu MSS et al was comparable in the Dexmedetomidine and clonidine groups at the time of administration of the drugs and there was decreasing trend of heart rate after administration of the drugs in both groups. [28]In a study by Raval DL et al, the pulse rate at all the time intervals were comparable between the two groups. ${ }^{[30]}$ The pulse rate in our study was higher in the Dexmedetomidine group than the clonidine group at 15minutes, $2 \mathrm{hr} 45$ minutes, at 3 hours and at the end of procedure. This contradicts the findings in studies by Swami SS et al, Babu MSS et al and Raval DL et al.

In the Swami SS et al study, it was observed that the systolic and diastolic blood pressure in the Dexemdetomidine group was significantly lower than the clonidine group from 30 to 120 minutes. ${ }^{[27]}$ The systolic blood pressure in our study was significantly higher in the Dexmedetomidine group than the clonidine group at all the time intervals except at baseline and 3 hours. The diastolic blood pressure in the Dexmedetomidine group was higher than the clonidine group at 10, 30, 60 minutes, $1 \mathrm{hr} 45 \mathrm{~min}, 2 \mathrm{hr} 45 \mathrm{~min} 3$ hours and at the end of procedure. The Swami SS et al study and our study produce conflicting results regarding variation in systolic and diastolic blood pressure between the two groups.

The peripheral oxygen saturation greater than $96 \%$ was present in the Dexmedetomidine and clonidine groups at all the times. ${ }^{[29]}$ In a study by Raval et al, all patients had peripheral oxygen saturation above $95 \%$ at all times. ${ }^{[30]}$ The peripheral oxygen saturation in all the patients in our study was more than $99 \%$ at all the time intervals.

None of the patients in both groups had any degree of respiratory depression in the studies by Bajwa SJS et al, Mahendru V et al, Raval et al, Babu MSS et al. ${ }^{[26,28,29,30]}$ This was similar to our study as there were no respiratory depression in patients of both groups. However, the initial respiratory rate at 0,5 minutes, $1 \mathrm{hr} 15$ min was higher in the Dexmedetomidine group compared to the clonidine group.

\section{Conclusion}

From above result to conclude that Onset of sensory block of clonidine is faster than Dexmedetomidine. Duration of sensory blockade was longer in clonidine group than the Dexmedetomidine group.

The time for onset of motor blockade was similar in clonidine and Dexmedetomidine group and is comparable in both groups. Duration of motor blockade was longer in clonidine group than Dexmedetomidine group.

There were no side effects found both in clonidine and Dexemedetomidine groups.

The quality of analgesia of these two drugs was relatively similar with nearly comparable duration of postoperative analgesia. The average age, weight, ASA distribution and sex distribution in two groups were comparable. 


\section{References}

[1]. Rawson R, Anastakis DJ, Von Schroeder H. Early but no long-term benefit of regional compared with general anesthesia for ambulatory hand surgery. Anesthesiology.2004 Aug; 101(2):461-7.

[2]. Popping DM, Elia N, Marret E, Wenk M, Tramèr MR. Clonidine as an adjuvant to local anaesthetic for peripheral nerve and plexus blocks: A meta-analysis of randomized trials. Anesthesiology 2009 Aug; 111(2):406-15. doi: 10.1097/ALN.0b013e3181aae897

[3]. Raimo V, Juha M, Veijo S, Leena N, Virtanen R. Characterisation of selectivity, specificity and potency of Dexmedetomidine as $\alpha 2$ adrenoceptor agonist, Eur J Pharmacol 1988;150:9-14.

[4]. Grey AT., ultrasound guidance for regional anesthesia ,In Miller's Anesthesia,Ronald.D.Miller 7th edition 2010; Churchill living stone Elsevier; $1675-1686$

[5]. Larson.M.D. History of anesthetic practice. In: Ronald D. Miller, Lars I Eriksson, Lee A Fleisher, Jeanine P, William Young, editors.In Miller's Anesthesia. 7th edition. Philadelphia:Churchill Livingstone Elsevier publications; 2010. p. 18-21

[6]. Winnie AP. Historical consideration. Chapters 2 and 4. Plexus Anaesthesia.New York: Churchill Livingstone 1984; 1:43-116,192202.

[7]. Chan VWS. Ultrasound imaging for regional anesthesia. 2ndedition.Chapter 1;2007:1-2

[8]. The peripheral nerves. In: Harold Ellis, S. Feldman, W. Harop Griffiths, editors. Anatomy for Anaesthetists. 8th edition. Blackwell Publishing Ltd; 2003. p. 153-179

[9]. Bannister LH, . Berry M M, Patricia Collins, Mary Dyson, Julian E. Dussek, Mery W. J. Ferguson, editors. Gray's Anatomy. 38th edition. New York: Churchill Livingstone; 1999. p .1266-74

[10]. Collins Vincent J, Editor. Principles of Anaesthesiology.3rd edition.Philadelphia : Lea \& Febiger ;1993.p. 1364-76

[11]. Interscalene Brachial Plexus Block. In: Admir Hadzic, editor. Hadzic's peripheral nerve blocks and anatomy for ultrasound guided regional anesthesia Edition. New York: McGraw-Hill Professional; 2011. p. 149 - 163

[12]. Axillary Brachial Plexus Block. In: Admir Hadzic, editor. Hadzic's peripheral nerve blocks and anatomy for ultrasound guided regional anesthesia. 2nd Edition.New York : McGraw-Hill Professional;2011.p. 186 - 195

[13]. Interscalene Brachial Plexus Block. In: Admir Hadzic, editor. Hadzic's peripheral nerve blocks and anatomy for ultrasound guided regional anesthesia. 2nd Edition. New York : McGraw-Hill Professional; 2011. p. 149 - 163

[14]. Salvatore Sia, Antonella L, Paolo P. Axillary Brachial Plexus Block Using Peripheral Nerve Stimulator: A Comparison Between Double- And Triple-Injection Techniques. Regional Anesthesia and Pain Medicine, Vol 26, No 6 9novemberdecember), 2001:pp 499-503

[15]. Axillary Brachial Plexus Block. In: Admir Hadzic, editor. Hadzic's peripheral nerve blocks and anatomy for ultrasound guided regional anesthesia. 2nd Edition. New York : McGraw-Hill Professional;2011.p. 186 - 195

[16]. The journal of the new york school of regional anesthesia (WWW.NYSORA.COM) may 2009 volume 12 by R By Alan Macfarlane BSc (Hons), MBChB, MRCP, FRCA and richard Brull MD, FRCPC.

[17]. Ultrasound for Regional Anesthesia (www.usra.ca/sb_supraclavicular).

[18]. Chan VW, Perlas A, Rawson R, Odukoya O: Ultrasound-guided supraclavicular brachial plexus block. Anesth Analg 2003; 97: 1514-7.

[19]. Charles B. Berde, Gary R. Strichartz. Local anesthetics. In: Ronald D. Miller, Lars I Eriksson, Lee A Fleisher, Jeanine P, William Young, editors. Miller's Anesthesia. 7th edition. Philadepldhia: Churchill Livingstone Elsevier publications; 2010. p. 913-940

[20]. Stoelting R, Simon C. Hillier, editors. Local Anesthetics. In:Pharmacology \& Physiology in Anesthetic Practice. 4th edition. Philadelphia: Lippincott Williams and Wilkins; 2006. p.179-207

[21]. Carteville W A, Kenneth Mackie. Local Anaesthetics. In: Bruton L.L,editor. Goodman \& Gilman's The Pharmacological Basis of Therapeutics. 12thedition. New York: Mc Graw Hill;2010. p .565-582

[22]. Lowenthal, DT; Matzek, KM; MacGregor, TR (May 1988). "Clinical pharmacokinetics of clonidine.". Clinical Pharmacokinetics 14 (5): 287-310. doi:10.2165/00003088-198814050-00002. PMID 3293868.

[23]. Venn R, Bryant A, Hall GM, Grounds RM. Effects of dexmedetomidine on adrenocortical function and the cardiovascular, endocrine and inflammatory responses in post-operative patients needing sedation in the intensive care unit. Br $\mathrm{J}$ Anaesth 2001;86:650-6

[24]. Yoshitomi T, Kohjitani A, alpha-2A adrenoceptor. Anesth Analg 2008;107:96-101. Maeda S, Higuchi H, Shimada M, Miyawaki T. Dexmedetomidine enhances the local anesthetic action of lidocaine via analpha-2A adrenoceptor. Anesth Analg 2008;107:96-101.

[25]. Venn RM, Hell J, Grounds RM. Respiratory effects of dexmedetomidine i the surgical patient requiring intensive care. Crit Care 2000;4:302-8

[26]. (Bajwa SJS, Bajwa SK, Kaur J, Singh G, Arora V et al. Dexmedetomidine and clonidine in epidural anaesthesia: A comparative evaluation. Indian J Anaesth. 2011 Mar-Apr; 55(2): 116-121.)

[27]. (Swami SS, Keniya VM, Ladi SD, Rao R. Comparison of dexmedetomidine and clonidine (a2 agonist drugs) as an adjuvant to local anaesthesia in supraclavicular brachial plexus block: A randomised double-blind prospective study. Indian Journal of Anaesthesia.2012;56(3):246-9.)

[28]. (Babu MSS, Verma AK, Agarwal A, Tyagi CMS, Tripathi S. A comparative study in the post-operative spine surgeries: Epidural ropivacaine with dexmedetomidine and ropivacaine with clonidine for post-operative analgesia. Indian J Anaesth. 2013 Jul-Aug; 57(4): 371-376.)

[29]. (Mahendru V, Tewari A, Grewal A, Singh MR, Katyal R. A comparison of intrathecal dexmedetomidine, clonidine, and fentanyl as adjuvants to hyperbaric bupivacaine for lower limb surgery: A double blind controlled study. J Anaesthesiol Clin Pharmacol. 2013 Oct-Dec; 29(4): 496-502.)

[30]. (Raval DL, Chaudhary M. A clinical comparative study between dexmedetomidine v/s clonidine with bupivacaine intrathecally in major orthopaedic lower limb surgery. Journal of Research in Medical and Dental Science.2014;2(1):77-82.)

[31]. (Solanki SL, Bharti N, Batra YK, Jain A, Kumar P, Nikhar SA. The analgesic effect of intrathecal dexmedetomidine or clonidine, with bupivacaine, in trauma patients undergoing lower limb surgery: a randomised, double-blind study. Anaesth Intensive Care. 2013 Jan;41(1):51-6.)

[32]. (Rao LN. A clinical study comparing clonidine with dexmedetomidine as adjuvants to local anaesthetic agent in brachial plexus block via inter-scalene approach for early discharge.IMTU.2014;5 